\title{
Listening and Understanding
}

\author{
Linda J. Parrott \\ West Virginia University
}

\begin{abstract}
The activities involved in mediating reinforcement for a speaker's behavior constitute only one phase of a listener's reaction to verbal stimulation. Other phases include listening and understanding what a speaker has said. It is argued that the relative subtlety of these activities is reason for their careful scrutiny, not their complete neglect. Listening is conceptualized as a functional relation obtaining between the responding of an organism and the stimulating of an object. A current instance of listening is regarded as a point in the evolution of similar instances, whereby one's history of perceptual activity may be regarded as existing in one's current interbehavior. Understanding reactions are similarly analyzed; however, they are considerably more complex than listening reactions due to the preponderance of implicit responding involved in reactions of this type. Implicit responding occurs by way of substitute stimulation, and an analysis of the serviceability of verbal stimuli in this regard is made. Understanding is conceptualized as seeing, hearing, or otherwise reacting to actual things in the presence of their "names" alone. The value of an inferential analysis of listening and understanding is also discussed, with the conclusion that unless some attempt is made to elaborate on the nature and operation of these activities, the more apparent reinforcement mediational activities of a listener are merely asserted without an explanation for their occurrence.
\end{abstract}

The behavior of the speaker is the focus of Skinner's (1957) book, Verbal Behavior. In his words, "an adequate account of verbal behavior need cover only as much of the behavior of the listener as is needed to explain the behavior of the speaker" $(1957$, p. 2). The listener's part in this explanation is constituted of the production of reinforcement for the speaker's behavior; and it is, therefore, the reinforcement mediational activity of the listener that is given primary coverage in the book. It is my view, however, that the listener's response to verbal stimulation involves activities which are neither identical with, nor necessarily a phase of, the activities involved in mediating reinforcement for a speaker; and that these activities, namely "listening" and "understanding what a speaker has said," must also be addressed if a complete account of the speaker-listener interaction is to be accomplished. The purpose of this paper, then, is to formulate

An earlier version of this paper was presented at the first European Meeting of the Experimental Analysis of Behavior, Liege, Belgium, July 1983. I thank Jack Michael, Philip N. Hineline, and Edward K. Morris for their comments on earlier drafts of this paper. Reprints may be obtained from Linda J. Parrott, Department of Psychology, West Virginia University, P.O. Box 6040, Morgantown, WV 26506-6040. an account of these less obvious activities, with the hope that it may serve as an elaboration and extension of the Skinnerian interpretation of verbal behavior.

It is not my intention to suggest that Skinner has failed to address himself to issues of listening ${ }^{1}$ and understanding altogether, but rather that the significance of these concepts in the analysis of psychological language events is overlooked. To substantiate this claim, Skinner's views of listening and understanding, and the contexts in which they are addressed, must first be examined.

\section{LISTENING AND UNDERSTANDING}

\section{Listening}

Listening is most often discussed in the general context of perception, not verbal behavior (Skinner, 1964, pp. 251-253; 1974, pp. 82-86). In this context, listen-

\footnotetext{
'Skinner prefers the term "hear" to "listen" in the sense that I am using it here. He regards "listening" as a precurrent response to "hearing," as is suggested by the following quotation: "One may look without seeing and listen without hearing, at least before seeing and hearing," (Skinner, 1969, p. 252). This distinction is not relevant to the present argument and the term "listening," where it appears, should be understood as including the orienting as well as the perceptual response systems.
} 
ing is conceptualized as operant behavior maintained by the consequence of "what is heard" $(1964$, p. 252). Seeing and other perceptual activities are similarly analyzed (1974, p. 78). Peterson and Michael (1982) suggest that reinforcements of this sort, in as much as they do not depend on mediational activities of other persons, are automatic in nature. In the context of verbal hehavior, however, the listener's behavior is not explained simply by appeal to the reinforcing value of what is heard. Instead, an explanation for the listener's behavior is to be found in the subsequent behavior of the speaker, which may take the form of verbal approval, gratitude, or threat withdrawal (Skinner, 1957, pp. 38-39, 84-85). This descrepancy between formulating listening in terms of automatic reinforcement for hearing and in terms of what the listener does arises because it is reinforcement mediation and not listening per se that is at issue in the context of verbal behavior.

\section{Understanding}

Skinner has also not failed to address the issue of understanding (1957, pp. 277280, 357-367; 1974, pp. 141-147). Understanding reactions are conceptualized as varying in complexity from simple echoic behavior, through some form of appropriate responding, to knowing something about the controlling variables of verbal behavior (Skinner, 1974, pp. 141-142). This analysis is not without its problems from the standpoint of attempting to identify a distinct and significant concept of understanding. In the first place, to equate understanding reactions with echoic behavior is neither conventional nor particularly valuable. Making an echoic response to verbal stimulation in an unfamiliar language is not what is ordinarily meant by the term "understanding" and no useful purpose is served by reducing a complex phenomenon to a simplier one and then changing the meaning of the term to accommodate the simplier phemonenon. Skinner does refine this analysis to suggest that something more than simple echoic respond- ing may be involved (1957, pp. 277-280). When he does so, he is exemplifying a much more complex form of understanding, as noted above, and to which we will return.

A second meaning of the term "understanding" from Skinner's perspective, amounts to responding appropriately to what has been said. There are two problems with this notion. First, it does not contribute to an analysis of understanding as a distinct, contemporaneous segment of behavior. Instead, it identifies this event with another more obvious activity of the listener, namely, reinforcement mediation. For example, to respond appropriately to verbal stimulation of the form "close the door" may be to close the door, by which action the speaker's behavior is reinforced. The second problem with this analysis is that it fails to distinguish between cases in which one may be said to lack understanding, as indicated by a failure to close the door, and those in which one simply does not comply with this request for other reasons.

This appropriate-responding analysis is also refined and extended by Skinner to include instances in which the appropriateness of the response is defined with respect to the circumstances giving rise to the speaker's behavior, as opposed to the verbal stimulation supplied by that behavior. Skinner mentions an example of this sort in Verbal Behavior, as follows: "When ... a listener blushes at the mention of a social error, he can be said to have understood what was said to the extent that his reaction was appropriate to the original event" (p. 277). As with the refinement of understanding as echoic responding, however, this elaboration exemplifies a more complex form of understanding, to which we may now turn.

Skinner's most complex form of understanding is described as understanding why a speaker has said what he has said. In Skinner's words, "To understand why, I must know something about the controlling variables, about the circumstances under which I should have said it myself" $(1974$, p. 141). To evaluate the adequacy of this description for our par- 
ticular purposes, we must first have some idea of what "knowing" amounts to in this context.

\section{Knowing, Knowledge, and Understanding}

Skinner approaches the problem of knowledge by identifying the variant circumstances under which the term is commonly used, with the result that a number of distinctly different interpretations of this concept are articulated (Parrott, 1983a). Among them is the view that knowledge is possessed as a repertoire of behavior (Skinner, 1957, p. 363; 1974, p. 138). The concept of a repertoire does not imply storage. Rather, it is a reference to the cumulative, and presumably biological changes in an organism brought about by its history of exposure to contingencies of reinforcement (Skinner, 1968 , p. 204). By this analysis, knowledge is not what the organism is doing at the present time, but instead, what it is capable of doing: Knowledge is potential behavior (Skinner, 1957, p. 363).

In as much as this interpretation does not provide an account of knowing as a contemporaneous segment of behavior, it is not useful for present purposes. Still, however, one implication of knowledge as potential behavior is that a person may be said to know something prior to the immediate occurrence of overt behavior indicative of such knowledge, and an interpretation of these events would be of considerable value. Skinner seems to be reluctant to comment on such knowing, however. He dismisses consideration of it as a "hypothetical intermediate condition which is detected only at a later date" (Skinner, 1957, p. 363). Accordingly, we need concern ourselves only with known (or inferred) histories of exposure to contingencies of reinforcement, and the overt behaviors to which they give rise. ${ }^{2}$

${ }^{2}$ In the interests of completeness, Skinner (1974, p. 140) also discusses a concept of knowledge short of action, which he describes as contemplative knowledge. He does not appear to want to abandon the knowledge as action interpretation, however. To preserve it, the action that is missing on the part
Knowing as action, then, constitutes the only interpretation of this concept of potential value in formulating an account of listening and understanding. Skinner's interpretation of knowing as acting $(1953$, p. 140,$409 ; 1974$, p. 138$)$ is quite straightforward. Two kinds of knowing as acting are distinguished on the basis of the manner in which such action is acquired, either by direct exposure to contingencies, or indirectly, by exposure to contingency-specifying rules (Skinner, 1974, pp. 138-139). In Skinner's (1974, p. 139) words: "We do not act by putting knowledge to use; our knowledge is action or at least rules for action." The distinction between rule-governed and contingency-shaped knowing is not important for our purposes. What is important are the kinds of contingencyshaped knowing identified by Skinner $(1974$, p. 138). By examining these activities, we may discover what it means to "know something about the controlling variables for a bit of verbal behavior."

Three types of knowing as acting are differentiated by Skinner (1974, p 138) on the basis of the complexity and multiplicity of the response topographies involved: "simple knowing," "knowing how," and "knowing about." It is "knowing about" that is of interest in the context of understanding. According to Skinner, to know something about the controlling variables for a bit of verbal behavior means that a listener has acquired a relatively large number of responses under an equally large number of variant circumstances in which these controlling variables have played a significant part (Skinner, 1974, p. 138). Re-

of the contemplative knower, as speaker, becomes action on the part of the knower as his/her own listener. Should such action become overt, then contemplative knowledge is indistinguishable from knowledge as action. If it does not become overt, then it falls into one or the other of the following categories: potentially overt behavior (i.e., a repertoire); private events, about which access is limited and little is said apart from how we learn to talk about them (Skinner, 1953, p. 257; 1957, pp. 130-138; 1974, pp. 21-32); or hypothetical intermediate conditions to be detected only at a later date. 
lating this analysis to the concept of understanding, we may conclude that the listener understands what the speaker has said when he/she is able to respond in multiple ways to stimulation having that form. It is this multiplicity of responding that is implied in Skinner's suggestion that something more than simple echoic behavior may be involved in understanding reactions, as previously mentioned. Specifically, understanding what someone has said involves, in addition to echoic behavior, a tendency to say the same thing under the control of related nonverbal and intraverbal stimulation (Skinner, 1957, pp. 277-280). Likewise, when Skinner refines the notion of understanding as appropriate responding to include responses appropriate to the circumstances giving rise to the speaker's behavior, as opposed to the verbal stimulation supplied by that behavior, he is suggesting that the listener's understanding reaction has the character of a tact relation (Skinner, 1957, p. 277).

In these cases, Skinner is not suggesting that tacts or intraverbals occur in an instance of understanding, as separate successive reactions. After all, the nonverbal stimulation required for a tact may be absent, making the occurrence of a tact impossible by definition. Rather, he is suggesting that these reactions would occur given an arrangement of conditions under which they could occur. They are aspects of a repertoire accumulated over the course of past experiences with contingencies of reinforcement (and with rules derived from them) involving tacts and intraverbals, and may be regarded as potential, as opposed to actual, reactions in the present moment.

The occurrence of listener reactions to the original conditions responsible for the speaker's behavior, as suggested in the refinement of understanding as an appropriate reaction, is a somewhat different case in that Skinner seems to imply that the listener's reaction is controlled by stimulation that is obviously missing from the current situation. His example $(1957$, p. 277$)$ suggests that a listener blushing at the mention of a social error understands what has been said in the sense that his reaction is appropriate to the actual events of social blundering, as opposed to their mere mention (Skinner, 1957 , p. 277). He does not give an account of how responding to stimuli in their absence can occur, however. Hence, it is my opinion that what Skinner is saying here is only that the term "appropriate" requires a statement of context to give it meaning. In other words, the listener's reaction is appropriate to circumstances that do not currently prevail, but the reaction occurs under the control of current auditory stimulation, and is, in this sense, not an instance of the tact relation.

In summary, according to Skinner, understanding is a construction, not an event. It refers to a repertoire of behavior and its potential for occurrence on given occasions of suitable stimulation. Note, however, that a repertoire is also a construction, as is its potential for occurrence. As such, "to know about" or "to understand" is really nothing at all until it eventuates in some form of overt behavior. That is, from an event standpoint, understanding amounts to whatever it is a listener does in response to verbal stimulation. And, given the focus of Verbal Behavior, the only relevant activity of the listener in this context is constituted of the mediation of reinforcement for a speaker's behavior (Skinner, 1957, p. 2).

\section{Further Considerations}

At this point, we must ask whether there is room in behavior analytic theory for a concept of understanding that is neither obscured by relegation to "potential" status, nor overlooked by way of identification with reinforcement mediational activity. Is there no place for distinct, contemporaneous segments of behavior called "listening" and "understanding what the speaker has said"? Before attempting to provide an account of such activities that is essentially in keeping with the radical behavioral perspective on psychological language events, it may be worthwhile to confront the arguments in support of Skinner's almost 
exclusive concern for the overt reinforcement mediational activities of listeners.

In defense of Skinner's position, it might be argued that he concentrates on reinforcement mediational phenomena because these are the only readily observable phases of the listener's participation in a verbal episode. Skinner would argue that if listening and understanding were to be formulated as contemporaneous events, they would have to be conceptualized as "private" events, inferred on the basis of subsequent overt performances presumed to be dependent upon them. Reinforcement mediation is one such overt performance. By this logic, until technologies are developed to make private events of this sort amenable to direct observation, an adequate analysis of their form and operation cannot be made.

This is a compelling argument, but only under a limited set of circumstances, namely, when one wishes to conduct empirical investigations into the nature and role of listening and understanding. $\mathrm{Ob}$ viously, our views and emphases concerning a particular subject matter must comport with our intentions concerning it. But, is empirical investigation what we are trying to do? Is this what Skinner was doing when he wrote Verbal Behavior? I think not. What Skinner and others have proposed with respect to psychological language events is an analysis-a conceptual analysis - not a collection of findings nor even a method for their collection. The point is that while the ready observability of phenomena may be required for empirical investigation, it is not required for conceptual purposes, and in as much as it is my intention to evaluate the completeness of Skinner's conceptual analysis of verbal interaction, I must argue that his neglect of listening and understanding reactions calls for remediation. The relative obscurity of these events does not render them inscrutable, nor does it detract from their significance in psychological language events. It simply calls for a more inferential or speculative type of analysis than is required of readily observable reinforcement mediational activity.

\section{A REFORMULATION OF LISTENING AND UNDERSTANDING}

If listening and understanding are behavioral events other than reinforcement mediation, the questions before us now are how these events are to be identified and what difference it makes to identify them. I will start with the first question, beginning with an analysis of the concept of listening. Note that I am using the term listening in a broad enough sense to include hearing as well. Further, what I am proposing about listening applies equally well to reactions with respect to visual and tactile modes of verbal stimulation.

\section{Listening}

As a psychological event, listening may be described as a functional relation obtaining between the responding of an organism and the stimulating of an object. Like all psychological events, listening functions are historical and corrigible, which is to say they evolve over the course of repeated occurrences throughout the behavior life of particular organisms. From this perspective, a current occurrence of listening is simply a point in the evolution of similar occurrences; it is continuous with and a composite of past instances of listening.

When I hear a particular sound-the sound of my name, for instance-I am interacting not only with this auditory stimulus as it is occurring at this moment, but also as it has occurred at other times throughout my life history. This is why a poorly executed vocalization of my name, producing a muffled or distorted sound, is still heard as my name by me, or by anyone else with the same name or who, for whatever reason, is particularly familiar with auditory stimulation of this form. For someone with a less extensive history of hearing the sound of my name, the muffled or distorted presentation of it in the present moment may be wholly unintelligible.

By way of explanation, we might say that the current auditory stimulation, because it bears some similarity to earlier occurrences of the sound of my name, is 
effective in evoking historical listening reactions. These reactions are not discrete sequential occurrences, though. They are aspects or phases of a composite form which includes, as well, a reaction to the poorly executed vocalization of my name in the present moment. To reiterate, the current act of listening is simply a point in the evolution of listening acts coordinated with stimuli bearing some formal similarity.

Let me provide another example, this time of a visual reaction. When I see my face in a mirror, I am interacting with this visual stimulus as it appears at this moment, as well as how it has appeared at other times over the course of my life. My long history of seeing my own face cannot help but make my seeing it different from someone else's seeing it for the first time. I may look younger to myself than to an unfamiliar person, for example. This is the case because the visual stimulation arising from my reflection in the mirror at this moment bears some resemblance to reflections of this form observed by me over the course of my life. My past seeing reactions coordinated with those reflections constitute phases or aspects of my current reaction. The current act of seeing, as with listening, is a point in the evolution of seeing reactions coordinated with stimuli bearing a formal resemblance.

J. R. Kantor and other interbehaviorists (Kantor, 1924, pp. 295-315; Kantor \& Smith, 1975, pp. 198-201; Pronko, 1980 , pp. 382-384) have described seeing and other perceptual events as "semi-implicit" acts, as a way of acknowledging the conjoint operation of current and historical stimulus functions in this context. In their terms, a current stimulus participates in two functions, one explicit and one implicit. The explicit function is simply the relationship obtaining between a stimulus as it appears in the present moment, and the reaction coordinated with it. The implicit function is that obtaining between previously encountered stimuli of similar form and the reactions coordinated with them, occurring in the present moment through the substitution of a current stimulus for past stimuli. In other words, a current stimulus substitutes for previously encountered stimuli such as to bring about reactions to those stimuli, despite their absence in the current situation. These historical reactions combine with the reaction coordinated with the current stimulus, producing a composite and unique response.

This view of perception has the effect of making the past an aspect of the present: One's history of perceptual activity may be regarded as existing in one's current perceptual behavior. It has no other locus and no other dimensions. It requires no storage, assumes no modification of the organism, and has no effect on current behavior. It is current behavior or, more precisely, current interbehavior. Further, unless one is willing to argue that we make some sort of extrasensory contact with our environment, what I am suggesting with respect to perceptual behavior applies to all of our behavior because perceptual activities are integral phases of everything we do. ${ }^{3}$

In summary, one of the activities of a listener in a verbal episode is the act of listening. Admittedly, it is an activity that defies direct observation. This may, in fact, be the reason for Skinner's neglecting to provide an analysis of it in the book, Verbal Behavior. It is the reason why verbal reports of having listened are adopted as evidence of listening. The two are not synonymous, however, and when one's goal is to provide a conceptual analysis of listening, evidence in the form of measurable occurrence is not at issue and its absence raises no difficulty. ${ }^{4}$ What is at issue is the participation of a listener in a verbal episode and no account of that participation, in which the act of listening per se is neglected, may be considered complete. The foregoing, thereby, is offered as an elaboration or extension of

\footnotetext{
${ }^{3}$ It should be clear that I use the term "perception" to refer collectively to such activities as seeing, hearing, smelling, etc., and in no way am I implying events of nonnatural dimensions.

4 Scientifically significant conceptual analyses are not the products of free construction, of course. They are derived from analyses of observable events and may be regarded as continuations of those analyses.
} 
Skinner's original account of the role of the listener in a verbal episode.

\section{Understanding}

Like listening, understanding may be conceptualized as a functional relation obtaining between the behavior of a listener and verbal stimulation. An instance of understanding may be regarded as a point in the evolution of this relation; one that is both peculiar to current circumstances and reflects a history of like occurrences. Understanding reactions are considerably more complex than listening reactions, however. The complexity of understanding reactions has to do with the preponderance of "implicit" responding involved, to use Kantor's (1924) term. Implicit responding simply means that a response originally coordinated with one stimulus occurs in a situation in which this stimulus is absent because another stimulus has acquired the function of the first stimulus by virtue of their formal simularity or other significant relationship. In such cases, the second stimulus is said to substitute for the first. Any particular stimulus object may participate in a variety of functional relations with response factors, and more than one such relation may be ongoing at any given moment. That is to say, a muffled or distorted vocalization of my name may at the same time be heard as a distortion as well as be recognized as a clear articulation.

Before applying this logic to the complex case of understanding reactions, it may be helpful to review the simpler case of listening. In describing the means by which current stimuli bring about historical listening reactions, it was argued that current stimuli substitute for like stimuli encountered on earlier occasions, thereby giving rise to listening reactions that had been coordinated with those stimuli on those earlier occasions. The similarity of current and historical stimuli was regarded as the basis for the development of substitute stimulus functions in these examples. There are other bases for the development of substitute functions, however. The proximity of stimuli in space and time may also serve in this capacity. For example, auditory stimuli are very often encountered in conjunction with visual stimuli. We often see dogs and hear them bark at the same time; we hear thunder in conjunction with seeing lightning. As a result of this pairing of activities in our experience, the performance of one such activity, say, hearing thunder, may give rise to at least some part of the activity involved in seeing lightning, even when there is no lightning to be seen in the current situation. In this case, thunder substitutes for lightning, not because thunder and lightning are similar, but because their proximity of occurrence in our experience has led to a proximity of reactions, to which, in turn, we have reacted. That is, the occurrence of an audient response to thunder is a stimulus with which a reaction to the relationship between hearing thunder and seeing lightning is coordinated (Kantor, 1924). As a result, the occurrence of thunder stimulates a reaction to lightning.

The point I am trying to make in this regard is that it is not only one's history of perceptual activity with respect to stimuli of similar form that comes to bear in the present, but also one's history of responding in other ways that have occurred in conjunction with these perceptual reactions. It is the availability in the present moment of these historically associated reactional events that makes for the greater complexity of understanding reactions.

\section{Understanding in a Verbal Context}

It is not understanding in general that is at issue, though. Rather, my intention is to provide an analysis of understanding from the standpoint of the listener in a verbal episode. To do so, we must consider the relative serviceability of verbal stimuli as substitutes for other stimuli.

Verbal stimuli are more serviceable as substitute stimuli than any other sort of event because of the nature and operation of verbal responses. Verbal responses have no direct effects on the stimuli with which they are coordinated, 
as Skinner (1957, pp. 1-2) has pointed out. The window does not close upon being asked to do so. Instead, the effects of verbal responding on the physical environment occur through the nonverbal actions of a listener. It is the listener's nonverbal behavior that has an effect on the window. This characteristic of verbal behavior makes for a number of other peculiarities, two of which are relevant to the present discussion.

First, because verbal responses have no direct effect on the stimuli with which they are coordinated, their occurrence does not in any way interfere with the execution of nonverbal responses coordinated with these same stimuli. ${ }^{5}$ For example, one can say "window" without interrupting the nonverbal behavior of closing a window. On the contrary, closing a window is likely to interrupt other ongoing nonverbal behavior with respect to a window, such as hanging a curtain rod. As a result, verbal responses are more frequent accompaniments of nonverbal responses to the same stimuli than are other nonverbal responses. Further, because perceptual (i.e., seeing, hearing, touching, etc.) activities are inevitable components of all nonverbal responses, verbal responses occur in conjunction with perceptual activities more often than with any other type of nonverbal behavior. In other words, saying "window" is likely to have occurred more frequently in conjunction with seeing a window than with closing a window, or hanging a curtain rod, or washing a window, or any other response coordinated with the object window. This is the case because seeing a window is involved in each of these other activities and occurs as well in the absence of any of them. I will deal with the implications of this analysis upon first describing a second distinctive feature of verbal responding.

Verbal response forms are not conditioned by their effects on the environ-

\footnotetext{
s There are, of course, exceptions. Nonverbal responding executed with the same musculature as verbal responding will interfere with the latter. One cannot say "flute" while at the same time playing one.
}

ment in the same manner as are nonverbal responses. This, again, is because verbal responding has no direct effect on the physical environment. For example, not all nonverbal response forms are equally successful in opening a window. Only those in which sufficient pressure is applied against a particular surface will have the effect of opening the window. These conditions determine the form of window opening responses. Verbal responses coordinated with the object window may vary considerably, however, and in ways unrelated (or very remotely related) to the physical properties of windows, as the multiplicity of names for window in the different languages around the world amply demonstrates. In short, verbal responses display an arbitrariness of form not found among their nonverbal counterparts. There are, thereby, practically no limitations on the extent to which response forms may vary. As a result, they exist in enormous variety, corresponding to the enormous variety of things and events of the physical world. In fact, the development of language for both individual and larger community consists, in large part, of each physical object or event, as well as each of their various aspects or properties, becoming coordinated with a verbal response having a form peculiar to that object and that object alone.

This specificity of correspondences between nonverbal stimuli and verbal response forms explains the greater serviceability of verbal stimuli over nonverbal stimuli as substitutes: Verbal stimuli acquire the functions of nonverbal stimuli more readily and more specifically than do other nonverbal stimuli. As such, when verbal responding occurs under conditions other than those giving rise to the tact (i.e., in the absence of relevant nonverbal stimuli), the stimulation supplied by such responding to a listener may give rise to nonverbal reactions normally occurring under other conditions. The reactions thus brought about are those having a history of frequent conjunctive occurrence with verbal stimuli of this form. As previously argued, the nonverbal reactions of most 
frecuent conjunctive occurrence with any given verbal response form are perceplual in nature, and it is this sort of nonverbal responding that occurs by way of substitute stimulation. In short, upon hearing the word "pigeon" in the absence of a pigeon, one may "see" a pigeon, "hear" it coo, "smell" it, or otherwise react to it. In this sense, at least, our reactions to the word "pigeon" are similar (1) the reactions we would make to an uctual pigeon, and it is this similarity of responding which is implied by the concept of substitute stimulation.

In summary, we react to events in their ubsence through the operation of substilute stimuli, and verbal stimuli are more scrviceable in this regard than are other events as a result of their ready occurrence in conjunction with other response cvents-notably perceptual responsesand the specificity of their correspondences with stimuli. ${ }^{6}$

\section{I irbal Behavior in the Social Context}

This conceptualization of the role of verbal stimuli is in keeping with the widely held view that language is an evolutionary product of cultural conditions under which extensive cooperation "Imong individuals has had some survivil advantage. Speaking is a means of inducing listeners to act in a coordinated iir cooperative manner or, as Skinner (1957, p. 225) has suggested, the behaviivr of the listener is conditioned "preriscly in order to reinforce the behavior "f the speaker." The evolution of lannuage presumably occurred in stages, however, and it is probable that language activities in the earliest stages of their development included only pointing reactions and a relatively small number of wther gestures useful in situations in which both speaker and listener were in direct perceptual contact with the things and

\footnotetext{
- The difference between verbal and nonverbal response forms, with regard to their serviceability is substitute stimuli, underlies the game of charades. If nonverbal response forms could bring about reactions to events in their absence as readily as verbal response forms, there would be no game of charades.
}

events about which cooperative or coordinated action was required. As collective living arrangements became increasingly complex and the circumstances requiring coordinated action became increasingly diverse, this gestural repertoire would undoubtably expand to the point of including vocalizations specifically coordinated with particular features of the nonverbal environment. Speaker actions of this sort would allow for greater precision and efficiency of action on the parts of listeners. It is possible also that this latter development took place as circumstances arose requiring cooperative or coordinated action with respect to things with which only the speaker or neither speaker nor listener was in direct perceptual contact. The substitutional functions of vocalizations coordinated with particular features of the nonverbal environment would have their greatest significance under such conditions. In fact, until the substitutional functions of vocalizations were operative for both speakers and listeners, precise reactions of listeners with respect to things and events absent from the immediate situation could not be induced by speakers. The development of these functions of verbal stimuli underlies the concept of "understanding what the speaker has said," to which we may now turn.

Understanding what the speaker has said is seeing, hearing, touching, or otherwise reacting to actual things and events in the presence of stimulation supplied by their "names" alone. It is not a series of such activities occurring in chain-like fashion over some extended period of time. Rather, understanding is a configuration of perceptual activities, as well as historically associated vestigal reactions of other sorts, coming to bear at the moment of contact with what the speaker has said. A contemporary understanding reaction is a point in the evolution of what may be an enormous number of reactions that have occurred in conjunction with both the thing spoken of and the verbal stimulation coordinated with it over the course of a listener's entire reactional history. Understanding is not a repertoire of potential behavior. It is 
an actual occurrence and one which proceeds and conditions subsequent actions, such as the mediation of reinforcement for a speaker's action. Understanding, further, has no causal role in this sequence. The relationship between understanding and mediating reinforcement is merely temporal, as is the relation between listening and understanding.

The present analysis is different from Skinner's position. Understanding is not an event from Skinner's perspective; it is a construction derived from other constructions, among them the behavioral repertoire. The repertoire is a construction referring to past behavioral occurrences and their potential for future occurrences. Apart from this suggestion of potentially, the repertoire, as conceived in the present moment, consists of some accummulation of organismic changes brought about by exposure to contingencies of reinforcement. These organismic changes are hypothetical in nature, however. They are not concrete biological facts, and reference to them in the explanation of psychological conduct has two implications. First, the explanation must be regarded as a hypothesis, not a documented fact. Other hypotheses are thereby worthy of consideration. Second, the appeal to hypothetical biological changes for an explanation of psychological events has the effect of thwarting further psychological inquiry. Discovering the nature and role of these biological changes becomes the occupation of biologists; not psychologists.

The present analysis may be described as an attempt to extend our understanding of psychological events at a psychological level of analysis. It is an attempt to give act status to the construct of a repertoire, along with the implications of this formulation for the concepts of listening and understanding.

\section{WHY SPECULATE ON THE NATURE OF LISTENING AND UNDERSTANDING?}

We come at last to the question of what value there may be in making inferential or speculative analyses of this sort. Why not simply agree, with Skinner, that a listener's response to verbal stimulation consists of the production of reinforcement for a speaker's behavior?

There are two reasons for attempting to provide an analysis of listening and understanding apart from reinforcement mediation. First, despite the subtlety' of these activities, they do occur and to neglect them results in an incomplete analysis of listener behavior. Moreover, even though the occurrence of these activities is implied whenever reinforcement mediation takes place, we cannot avoid making a separate account of listening and understanding on this basis because listening may occur without understanding and understanding may occur without reinforcement mediation. Hence, when either of these situations prevails, an account of listener behavior limited to reinforcement mediational activity is inadequate.

Second, nonbehavioral psychologists have not ignored these phenomena, and their accounts, for this reason, may be considered more complete. Hence, to whatever extent completeness is a virtue, endorsements of nonbehavioral psychologies may be anticipated. The interpretations of listening and understanding arising out of these sources are inconsequential and misleading, however, because listening and understanding are interpreted as mental events taking place in nonexistent internal structures. (It should be noted, as well, that this interpretation cannot be salvaged by recent attempts to substitute the brain for the mind as the operative agent in such events. This is simply subterfuge.) Genuine scientific advancement in our understanding of subtle psychological events cannot be expected to occur against a background metaphysical philosophy. Nor can it be expected as an outcome of

\footnotetext{
'The term "subtle" is used here to avoid a confusion of the present analysis with the notion that events of this sort are private in the sense of occurring in some location within the skin. The author contends that all psychological events involve actions of the whole organism, not its parts considered separately. (For a more detailed discussion of this issue, see Parrott, 1983b).
} 
innoring events of this sort altogether, as brhavioral psychologists have been prone ii) do. On the contrary, if we are to cullivate a thoroughgoing science of behavior. we must extend our analytical and investigative methods to all behavioral events, including those that present prob$\mathrm{lems}$ of observation. Extensions of this sort do not imply a commerce with mentalism. The present analysis of listening and understanding assumes only that onc's history of interacting with stimuli includes interactions with relational events, and further, that this history is an aspect of one's current behavior. The unalysis is thoroughly naturalistic.

Finally, and in conclusion, unless some Iltcmpt is made to elaborate on the nature and operation of the listening and understanding reactions of a listener, the wcurrence of reinforcement mediational nctivities is merely asserted without explanation. That is, in order for a listener (1) mediate reinforcement for a speaker's "mand," for example, the listener must bo assumed to have heard and understood what the speaker has said. These activities condition the listener's overt reaction. How else can we account for a listener's closing a door upon encountering the auditory stimulus "please close the door"? By what means is the listener's action directed toward the door? How does the transfer of control from the auditory stimulus "door" to the actual objict, door, occur? What exactly is it that the listener is doing under such condi- tions? It is to answer these questions that an analysis of the present sort is directed.

\section{REFERENCES}

Kantor, J. R. (1924). Principles of psychology. Chicago: Principia Press.

Kantor, J. R., \& Smith, N. M. (1975). The science of psychology: An interbehavioral survey. Chicag0: Principia Press.

Parrott, L. J. (1983a). Perspectives on knowing and knowledge. The Psychological Record, 33, 171-184.

Parrott, L. J. (1983b). Systemic foundations for the concept of "private events": A critique. In N. M. Smith, P. T. Mountjoy, \& D. Ruben (Eds.), Reassessment in psychology: The interbehavioral alternative (pp. 251-268). Washington, D.C.: University of America Press.

Peterson, M. E., \& Michael, J. (1982). Automatic reinforcement: An important but ignored concept. Behaviorism, 10, 217-227.

Pronko, N. H. (1980). Psychology from the standpoint of an interbehaviorist. New York: BrookCole.

Skinner, B. F. (1945). An operational analysis of psychological terms. Reprinted in B. F. Skinner (Ed.), Cummulative Record. A selection of papers (pp. 370-384). New York: Appleton-CenturyCrofts.

Skinner, B. F. (1953). Science and human behavior. New York: The Free Press.

Skinner, B. F. (1957). Verbal behavior. New York: Appleton-Century-Crofts.

Skinner, B. F. (1964). Behaviorism at fifty. In T. W. Wann (Ed.), Behaviorism and phenomenology: Contrasting bases for modern psychology (pp. 79-108). Chicago: University of Chicago Press.

Skinner, B. F. (1974). About behaviorism. New York: Knopf.

Skinner, B. F. (1978). Why I am not a cognitive psychologist. In B. F. Skinner (Ed.), Reflections on behaviorism and society. Englewood Cliffs, NJ: Prentice-Hall. 